Bentham OPEN

\title{
Rapid Identification and Characterization of Francisella by Molecular Biology and Other Techniques
}

\author{
Xin-He Lai ${ }^{1,2, *, \#}$, Long-Fei Zhao ${ }^{3, \#}$, Xiao-Ming Chen ${ }^{1,2,4}$ and Yi Ren ${ }^{1,5}$ \\ ${ }^{1}$ Institute of Inflammation \& Diseases, The First Affiliated Hospital of Wenzhou Medical University, Wenzhou, China \\ ${ }^{2}$ Institute of Translational Medicine, The First Affiliated Hospital of Wenzhou Medical University, Wenzhou, China \\ ${ }^{3}$ College of Life Sciences, Key Laboratory of Plant-Microbe Interactions of Henan, Shangqiu Normal University, \\ Shangqiu, Henan, 476000, PR China \\ ${ }^{4}$ Department of Pediatric Surgery, The First Affiliated Hospital of Wenzhou Medical University, Wenzhou, China \\ ${ }^{5}$ Department of Biomedical Sciences, Florida State University College of Medicine, Tallahassee, FL, USA
}

\begin{abstract}
Francisella tularensis is the causative pathogen of tularemia and a Tier 1 bioterror agent on the CDC list. Considering the fact that some subpopulation of the $F$. tularensis strains is more virulent, more significantly associated with mortality, and therefore poses more threat to humans, rapid identification and characterization of this subpopulation strains is of invaluable importance. This review summarizes the up-to-date developments of assays for mainly detecting and characterizing $F$. tularensis and a touch of caveats of some of the assays.
\end{abstract}

Keywords: Francisella tularensis, molecular characterization, subpopulation typing, virulence.

\section{INTRODUCTION}

Due to its high infectivity to cause tularemia, relative ease of dissemination and prior stock as a biological weapon, F. tularensis subsp. tularensis (F. tularensis) is classified as a Tier 1 (Category A) agent by the Centers for Disease Control and Prevention (CDC), together with the other 5 members, i.e., Bacillus anthracis, Yersinia pestis, Clostridium botulinum toxin, Variola major, and viruses causing viral hemorrhagic fevers [1]. Francisella genus, a group of Gramnegative bacteria, is expanding rapidly and includes human pathogen $F$. tularensis, opportunistic pathogens such as $F$. hispaniensis, and F. philomiragia, numerous fish pathogens, and non-pathogenic Francisella like bacteria found in ticks and soil samples [2]. With some controversy, F. tularensis is described to consist of four subspecies: holarctica, mediasiatica, novicida, and tularensis [2].

By CDC definition, a confirmed tularemia is when $F$. tularensis is isolated from a clinical specimen or a four-fold or greater change in the $F$. tularensis antiserum titer and a probable case when $F$. tularensis is detected in a specimen by fluorescent assay or a single titer elevation of the F. tularensis antiserum [3]. The greatest risk of Francisella to laboratory workers is from exposure to its infectious aerosols from manipulation of Francisella cultures. Although still the gold-standard to validate an $F$. tularensis infection, cultivation of the organism is not routinely performed at most clinical laboratories because it requires a certain equipment, special containment and experience. Limitations in both culture and serology have led to substantial research in the development of new diagnostic techniques for $F$. tularensis.

Techniques, either new or old, such as biosensor, cell culture, lateral immunological flow, PCR, liquid- or solid based biochip, and analytical chemistry (gas chromatography and mass spectrometry, etc. ) or biochemistry - based

\footnotetext{
* Address correspondence to this author at the Institute of Inflammation \& Diseases, The First Affiliated Hospital of Wenzhou Medical University, Wenzhou, China; Tel: +86-15626509384; E-mail: laixinhe@yahoo.com

${ }^{\#}$ These authors contributed equally to this work.
} 
methods, have been developed and used for identifying and detecting $F$. tularensis. In particular, a variety of molecular typing methods can be used to characterize $F$. tularensis, including amplified fragment length polymorphism (AFLP), canonical insertion-deletions (INDELs), PCR, multilocus sequence typing (MLST), multilocus variable-number tandem repeat (VNTR) analysis (MLVA), pulsed-field gel electrophoresis (PFGE), ribotyping, regional difference (RD) analysis, whole-genome-based single nucleotide polymorphism (SNP) analysis and even whole genome sequencing (WGS)-based $\mathrm{MLST}^{+}$. Among them, PCR is the dominant method for direct detection of F. tularensis. In the United States, one can also consult the Laboratory Response Network (LRN) for reagents and protocols to aid in identification of Francisella species [4].

If human, animal and environmental samples are collected for epidemiological study when there is a tularemia or any infectious outbreak, the question will be what is in the specimen from a patient or from the environment? No organism can be detected in the sample? Only a single type of organism or a mixed population of organisms coexisting in the specimen? This review will focus on the rapid characterization, identification of $F$. tularensis, touch a bit of its differentiation from other Francisella strains and other Class A agents if needed, and divide this topic into different scenarios. One is F. tularensis is isolated and pure culture is available for analysis. Another is F. tularensis is there alone or together with other agents in the specimen or environment but the situation does not allow to culture the microorganism(s). We will discuss the strategy dealing with these oversimplified situations.

\section{IDENTIFICATION AND CHARACTERIZATION OF ISOLATED FRANCISELLA STRAINS}

When $F$. tularensis strain(s) is isolated and available, it is quite straight forward to use the quickest, most sophisticated technique available to do the job. The assays, either physical, chemical, or mainly molecular, to achieve the specific goal of the project, will be discussed.

\subsection{Direct Culture and Methods to Increase Isolation of Strains are Very Helpful}

A very recent report described that bacterial isolate from direct culture of blood samples in BacT/ALERT 3D was identified as F. tularensis with $99 \%$ probability by Vitek GN ID Cards [5]. Pavlovich's medium T was found optimal for enrichment of fastidious pathogen like Francisella upon re-evaluation [6]. DNA aptamers (single strand sequences) against Francisella alone fail to capture the target at low inoculums (1-10 cells/mL) [7]. An enrichment step with addition of $0.625 \mathrm{mg} / \mathrm{mL}$ of carnosine into conventional medium for $F$. tularensis to increase the growth of this specific bacterium at initial low inoculums, together with a DNA aptamer cocktail to physically separate $F$. tularensis from other bacteria present in food and environmental matrices, resulted in a detection range of $1-10^{6}$ colony-forming-unit $(\mathrm{CFU}) / \mathrm{mL}$ (starting inoculums) in both soil and lettuce backgrounds. This combined two-step enrichment process could be very useful for easy field diagnostics and subtyping of suspected F. tularensis contamination [7].

\subsection{Insertion-Deletion (INDEL) and Pulsed Field Gel Electrophoresis (PFGE)}

INDELs and PFGE, the two fragment-based methods, have been used to genotype $F$. tularensis strains. A new version of INDELs, canINDEL, together with CanSNPs (see below) was used to analyze 76 F. holarctica strains in Finland and helped to verify the diversity of this subspecies [8]. In PFGE, the banding patterns of DNA fragments (10 $\mathrm{kb}-10 \mathrm{Mb}$ in size) of the strains are compared after restriction enzyme digesting and electrophoresis separation of the bacterial genomic DNA, which is most extensively utilized to investigate population structure of $F$. tularensis strains and define them into three subpopulations, A1a, A1b, and A2 [9], which differ in their levels of virulence in animal, fatality rate $(4 \%, 24 \%$ and $0 \%$ mortality, respectively) and clinical outcome in human.

\subsection{Single Nucleotide Polymorphism (SNP)}

In clonally reproducing $F$. tularensis organisms, single nucleotide polymorphisms (SNP) are represented by evolutionarily stable point mutations and SNP analysis of the whole-genome and genotyping of strains using highdensity microarray and real-time PCR have been used to do the phylogeography of $F$. tularensis subspecies and their subclades [10]. Based on 16 SNP signatures, 179 strains previously designated as A1 subpopulations were further assigned to 15 F. tularensis subsp. tularensis A.I subpopulations, including group A.I.3 (4 subpopulations), group A.I.8 (4 subpopulations), group A.I.12 (previous A1a, 6 subpopulations) and one (ND01-1900) undetermined [11].

\subsection{Multiple-Locus Variable Number Tandem Repeat Analysis (MLVA)}

After analyzing genomes for variable-number tandem repeats (VNTRs), a multilocus VNTR analysis (MLVA) 
typing system has been developed for $F$. tularensis at the beginning of this century and demonstrated its applicability for rapid identification and characterization of outbreak isolates from an epizootic [12]. MLVA can genotype microbes by comparing the differences of the sizes of repetitive DNA in microbial genomes via PCR and subsequent fragment analysis. Upon utilizing 11 canonical SNPs, 4 INDEL markers and 5 VNTRs, the $1^{\text {st }}$ tularemia case in the Capital of China was determined as Type B and caused by a B3 clade F. tularensis of Russian origin [13].

\subsection{PCR}

About 20 years ago PCR was first introduced to distinguish Francisella strains at the genus, species, and subspecies levels using primers designed from the 16S rDNA sequence [14], much has been progressed since then from the format, the primer design to the automation level and potential as mentioned below and nicely reviewed elsewhere [15]. The importance of choosing the right PCR supplies like DNA extraction reagents, and some instruments were emphasized in some publications. RT-PCR and Taqman PCR will be discussed under the Section "SIMULTANEOUS DETECTION OF FRANCISELLA AND OTHER AGENTS".

\subsubsection{PCR Reagents}

Reagents play an important role in any PCR detection system. Lot-to-lot variation exists even in the same commercial DNA extraction kit (not to say another brand), a finding that emphasizes the necessity to construct standard curves for each new lot of PCR reagents for more accurate data interpretation. The cycle threshold $(\mathrm{Ct})$ values were statistically different among 3 different lots of the above mentioned commercial DNA extraction kit when it was used in a real-time PCR assays for F. tularensis, B. anthracis, and $V$. cholerae [16], in which replicate aliquots of the 3 bacteria were processed in duplicate and the experiment was repeated in triplicate.

Here is another example how commercial products can differ. For comparison purpose, 10 master mix products (ABsolute Fast QPCR Mix, Brilliant II FAST qPCR master mix, EXPRESS qPCR SuperMix kit, FAST qPCR master mix, the HotStart IT Taq master mix, LightCycler FastStart DNA Master HybProbes, LightCycler FastStart DNA Master (PLUS) HybProbe, OmniMix HS, QuantiFast Probe PCR kit, and the TaqMan Fast Universal PCR master mix) were used in real-time PCR assays for detection of 4 biothreat agents (F. tularensis, B. anthracis, B. mallei and B. melitensis). They performed well on the 7500 Fast Dx instrument [17], and positive results were most consistent from using the QuantiFast Probe PCR kit and random combinations of commonly used master mixes and instruments were not as reliable as others at detecting low concentrations of target DNA.

\subsubsection{DNA Extraction Methods for PCR}

DNA or RNA quality is of utmost importance for PCR reaction. The capacity to isolate F. tularensis quality DNA suitable for real-time PCR analysis from cell suspensions and spiked foam, cotton, and polyester swabs was compared among 2 automated methods (the QIAcube and the MagNA Pure Compact) and 4 manual methods (the IT 1-2-3 DNA sample purification kit, the MasterPure Complete DNA and RNA purification kit, the QIAamp DNA blood mini kit, and the UltraClean Microbial DNA isolation kit). Four of them ( 2 of the manual methods MasterPure and QIAamp and both the automated methods) did equivalently well for spiked swab samples and significantly better in detection from bacterial suspensions than the remaining two methods. Using a multitarget 5 ' nuclease assay resulted in the same PCR sensitivity for F. tularensis [18].

One of the confounding factors for PCR reaction is the presence of inhibitors in the sample. The capacity of 9 inhibitor-resistant PCR reagents to overcome PCR inhibition was assessed in an established real-time PCR assay for direct detection of $F$. tularensis in 7 different environmental and clinical samples. No reagent could outperform others in all of the different evaluated matrices (buffer, sand, soil, sputum, stool, swab, and whole blood). KAPA Blood PCR kit produced the most consistent results among the various conditions assessed, and 3 other brands (Phire Hot Start DNA polymerase, Phire Hot Start DNA polymerase with STR Boost, and Phusion Blood Direct PCR Kit) performed best for direct detection in whole blood. The only reagent yielding a limit of detection in the femtogram range for soil was Phire Hot Start DNA polymerase with STR Boost [19], indicating room for further improvement. A similar study specifically evaluated 5 kits (Puregene DNA purification kit, QIAamp Stool Mini kit, Epicentre Biotech SoilMaster DNA extraction kit, and the UltraClean and PowerMax soil DNA isolation kits) of their performance in extracting $F$. tularensis DNA from all types of soil samples and the 2 kits from MoBio (UltraClean and PowerMax) provided the lowest limit of detection (20 and $100 \mathrm{CFU} / \mathrm{g}$ soil, respectively) and came out positive consistently [20]. 


\subsubsection{PCR Instruments}

The performance of the Applied Biosystems 7300/7500 and the RAZOR instruments was compared in real-time PCR assay for specific detection of F. tularensis, B. anthracis, Brucella spp., and $Y$. pestis. Although the duration of thermocycling with the RAZOR instruments was shorter than that of the Applied Biosystems 7300/7500 instruments (40 vs $100 \mathrm{~min}$ ), their assay performance was not significantly different with a sensitivity at 10-100 fg of target DNA per reaction [21]. A portable real-time PCR instrument from PikoReal ${ }^{\mathrm{TM}}$ could obtain result within 95 min in field testing with sensitivity ranged from 1 to $100 \mathrm{fg}$ for $F$. tularensis, B. anthracis, and $Y$. pestis [22].

\subsubsection{PCR}

We will discuss the detail development of PCR below as exemplified by a recent publication [23] and focus on the findings about $F$. tularensis.

First of all, it was an assay combined with two closely-related multiplexed assays (multiplexed PCR sizing assay, Focused Sequencing assay with Sanger protocol), which seems a trend we will see more and more in the literature and these two assays were so closely-related that they could share the same set of primers. The two assays mainly differed in that Rapid Focused Sequencing could reveal additional variations (size neutral INDELs, SNPs) that would not lead to alterations of fragment size, and at the same time provide the same precision but more accurate sequence information of the continuous 500 base target locus fragments than whole genome sequencing (WGS) methods, which was almost impossible to achieve by quantitative PCR together with probe- or melt-curve- or microarray-based detection. In contrast to MLST methods, the choice for primers in the Rapid Focused Sequencing approach was more flexible and not limited to those neutral housekeeping genes and as a result the increase of targets made it better than PCR alone in its strain typing ability.

The fluorescently labeled 30-plex primer set was for PCR and unlabeled one for Rapid Focused Sequencing. In the $7 \mu 1$ reaction volume, the purified sample DNA was subjected to two slightly different multiplexed (in this work 30plex) microfluidic amplifications, one with fluorescently labeled primers and the other with unlabeled. The labeled amplification products were separated by microfluidic electrophoresis and the unlabeled ones were divided into 20 aliquots and diluted for Rapid Focused Sequencing. Each sequencing reaction contained a reverse or forward primer for a locus from any of the 3 microbes and the amplicon was separated and detected on a different electrophoresis channel.

Another feature of this assay was its extraordinary strain typing capacity accomplished by sizing the differential fragments of the resulting amplicons and discrimination ability among closely-related species based on selective primer binding, which enabled to detect $F$. tularensis, B. anthracis, and $Y$. pestis simultaneously by interrogation of 30 loci (10 each from the several pathogens) in a single reaction, fulfilling the purpose of multitasking, which is the direction of future assay development.

The $3^{\text {rd }}$ change in the assay design was the number increase and their broader representation of the detection targets. Taking advantage of the availability of tens of sequenced $F$. tularensis genomes, the authors selected a total of 10 target loci which were very representative and able to distinguish the 4 subspecies and strains within, including those of the type A1 and A2 clade. Specifically, the Francisella target panel included genes for antigen (fopA), metabolism ( $g y r$, speA), virulence ( $a c p \mathrm{~A}, i g l \mathrm{C}, p d p \mathrm{D})$, transcriptional regulation (FTT008, migR), and FTT0082 and pepO which were annotated as pseudogenes in certain strains including Schu S4. Designing multiple primers this way greatly reduces the risk of PCR failure due to any strain missing a chunk of genes, sometimes the whole Francisella pathogenicity island [24], which is extreme and rare.

Using template DNAs from reference strains representing each agent, the specificity and sensitivity of the primers were tested by singleplex PCR, indicating the continuous usefulness of singleplex PCR. To generate the 10-plex PCR F. tularensis panel, the primer pairs were combined sequentially after individual primer pair optimization and preliminary testing, and further used to examine 28 additional Francisella strains in PCR reactions containing Schu S4 DNA ca. 100 genome equivalents. Sequence analysis (including in silico) of fragments amplified from the 10 loci showed that a total of 21 Sequence Types (STs) exist in the $41 F$.tularensis isolates. All type A2 strains shared Sequence Type B and Type A1 strains had either ST A or C with no overlap in STs between F. tularensis and F. novicida subspecies. Therefore, Rapid Focused Sequencing is perfectly able to detect the presence or absence of $F$. tularensis-specific DNA, and unambiguously distinguish between subspecies (holarctica, novicida and tularensis) and between type A1 and A2 strains.

Last but not least, this newly developed technique was full of potential that in a single microfluidic biochip it could 
incorporate multiplexed amplification, nucleic acid purification, and electrophoretic separation and run rapid pathogen analysis in the field on both clinical and environmental samples. Furthermore, the assay could be modified in primer design, pathogen change, and target expansion.

Table 1. Comparison of some assays for Francisella and characterization.

\begin{tabular}{|c|c|c|c|}
\hline Assay & Resolution & Comment & Ref \\
\hline Culture & Genus & Time consuming, infection risk, low sensitivity & {$[5-7]$} \\
\hline Agglutination & Species & Simple, cost effective but with cross reaction & {$[36,65]$} \\
\hline LAT & Species & Fast (5 min), sensitive, specific without cross reaction & {$[31]$} \\
\hline ELISA & Species & 10 times more sensitive than TA but with delay post infection & {$[32-35]$} \\
\hline GNP-OLISA & Species & LOD 25 CFU/ml (37 times more sensitive than ELISA) & {$[38]$} \\
\hline SELDI-TOF/MS & Subspecies & Less loss, faster and simpler in sample prep than MALDI & {$[39,41]$} \\
\hline MALDI-TOF/MS & Species/subspecies & LOD 80 CFU, fast (10-30 min), simple, less peaks than SELDI & {$[40,41]$} \\
\hline Raman & Species/subspecies & Fast (15 min) but need strain isolation spectral library & {$[66,67]$} \\
\hline Sensor & Species & Fast (30 min), specific, sensitive (LOD $15 \mathrm{ng} / \mathrm{ml}$ ), simple & {$[30,37]$} \\
\hline Ribotyping & Species/subspecies & Fast but need strain isolation & {$[66,68]$} \\
\hline rRNA probe & Species & LOD 105 CFU/ml, involve RNA extraction & {$[69,77]$} \\
\hline AFLP & Subspecies & Less prone to lab infection, more time consuming than PCR & {$[67,70]$} \\
\hline RFLP & Species & Rapid, simple, involve gene amplification enzyme digestion & {$[70,71]$} \\
\hline PFGE & Subspecies & Less lab infection risk but need prior strain isolation & {$[9,70]$} \\
\hline MLVA & Strain & Robust, simple, fast but need strain isolation & {$[12,72]$} \\
\hline SNP & Subspecies/strain & rapid low-cost strain typing, suitable for evolution analysis & {$[10,73]$} \\
\hline PCR & Subspecies/strain & Fast, no strain isolation with false +/-, LOD $102 \mathrm{CFU} / \mathrm{ml}$ & {$[14,23]$} \\
\hline Taqman & Subspecies & Rapid, accurate, sensitive (LOD 1 CFU/GE) & {$[57,74]$} \\
\hline RT-PCR & Subspecies/strain & Faster less false positive than PCR, LOD 25 GE & {$[18,57]$} \\
\hline Microarray & Subspecies & Rapid, LOD 20 GE or $100 \mathrm{ng} / \mathrm{ml}$, compatible to multiple pathogen & {$[42,75]$} \\
\hline FilmArray needed & Genus & Sensitive, LOD 12.5 GE with $0.9 \%$ error rate, no experience & {$[49]$} \\
\hline LAMP & Species & Specific, LOD 25 GE or $50 \mathrm{fg} / \mathrm{ml}, 100 x$ sensitive than PCR & {$[76]$} \\
\hline MLST+ & Subspecies/strain & High resolution, superior to MLVA, able to assign genotype & {$[28]$} \\
\hline WGS & Strain & High resolution, limited number of strains, relatively costly & {$[25-27]$} \\
\hline
\end{tabular}

\subsection{Genome Sequencing and MLST+}

The availability of the ever increasing genome data allows more rational design and better selection of PCR primers and typing markers based on evaluation of previous published genetic markers, which will further reduce the laboratory costs and time spending in the development of the next generation of molecular differentiation methods for bacterial subspecies. Whole-genome sequencing (WGS), although affordable and thoroughly informative, should still be used as supportive rather than decisive and the last resort to solve the epidemiology mystery, which was demonstrated in a recent report cautioning not to completely rely on genome sequence data as proof of a direct $F$. tularensis epidemiological link [25]. WGS was also used to genotype $18 \mathrm{~F}$. tularensis strains isolated from 180 patients during a tularemia outbreak in Norway and they were assigned to clade B.6 (subclade B.7), clade B.12, and clade B.4 of subsp. holarctica [26]. WGS demonstrates that the less virulent A.II strains have more genomic plasticity than A.I strains, which might be the source of their differences in virulence and fitness [27].

An upgraded version of multilocus sequence typing system called MLST ${ }^{+}$based on WGS of 15 F. holarctica strains and a gene-by-gene approach has been developed and tested to investigate a lethal tularemia epidemic of non-human primates, and proved to be rapid with high resolution and superior to the current genotyping method [28]. Similar idea and practice have been encouraged for other pathogens during the GMI8 meeting in Beijing, China [29], which is in contrast to the comment made by reference [25].

\subsection{Other Techniques}

Two DNA probes (the $101 \mathrm{bp}$ probe unique for type A strains from the $y h h \mathrm{~W}$ gene and the $117 \mathrm{bp}$ probe common to type A and type B strains from the lpnA gene) were designed that the specific antigen could bind to the IgG fraction of $F$. tularensis antiserum coated on the optical fiber surface in a nanostructured film of the Fabry-Perot interferometric sensor, which would cause the decrease of peak wavelength and thus enable the detection of $F$. tularensis. Using a 
standard transmission mode long period $(260 \mu \mathrm{m})$ fiber grating of length $15 \mathrm{~mm}$, the sensors were capable of detecting the optical changes induced by the attachment either of the immunological binding or DNA hybridization to the fiber tip via layer-by-layer electrostatic self-assembly, and spectroscopic ellipsometry could measure the refractive index change. This assay was rapid, culture-free, field-compatible, and able to differentiate 2-bp mismatch sequence with a sensitivity of nanogram and $100 \%$ specificity to homologous target DNA [30].

\section{DETECTION OF FRANCISELLA WITHOUT ANY PURE ISOLATE}

\subsection{Serum-based Assays}

Antibody-based assays using specific antibody, either monoclonal or polyclonal, have been used in assays to diagnose $F$. tularensis infection, such as microscopy, microagglutination (MA) and ELISA. Recent developments have modified or combined these conventional assays and improved their performance in some degree as shown below.

The result of a latex agglutination test (LAT) was read within 5 min by mixing serum with $F$. tularensis antigencoated latex beads, which has proved to be a specific, sensitive, fast, easy-to-perform and cost-efficient tool for routine diagnosis of tularemia [31].

A competitive enzyme-linked immunosorbent assay (cELISA) has been tested in Japan for serosurveillance of tularemia among various species of wild animals and it was highly sensitive and useful [32]. Another cELISA was developed on the principle that antiserum could inhibit antigen binding to monoclonal antibodies (MAbs) directed against $F$. tularensis lipopolysaccharide (LPS) and used to detect serum samples of 50 healthy individuals and 19 tularemia patients, and compare with indirect ELISA (iELISA) and microagglutination (MA). The cELISA in this study had a sensitivity and specificity of 93.9 and $96.1 \%$, respectively, whereas MA was less sensitive (81.8\%) with a specificity of $98.0 \%$ [33].

The diagnostic accuracy of other versions of ELISA (Serazym ${ }^{\circledR}$ Anti- $F$. tularensis ELISA, Serion ELISA classic $F$. tularensis $\mathrm{IgG} / \mathrm{IgM}$, an in-house ELISA) in examining 135 sera (from a series of 110 consecutive tularemia patients) were compared with a Western Blot (WB) assay and the VIRapid ${ }^{\circledR}$ Tularemia immunochromatographic test, an in-house antigen microarray. All the commercial assays gave a diagnostic value above $90 \%$ and among them the antigen microarray test was predictive and very specific [34]. VIRapid, Serion IgG, Serion IgM, Serazym, in-house ELISA, WB and microarray had high diagnostic sensitivity $(97.0 \%, 96.3 \%, 94.8 \%, 97.0 \%, 95.6 \%, 93.3 \%$ and $91.1 \%)$ and specificity $(84.0 \%, 96.8 \%, 96.8 \%, 91.5 \%, 76.6 \%, 83.0 \%$, and 97.9\%), respectively [34]. Slightly lower or higher detection rates than the above report were obtained earlier with Virion/Serion ELISA assay for IgG and IgM antibodies, and tube agglutination test, lower in one study in 39 (68.4\%) serum samples obtained from patients suspected for tularemia [35], and higher in another with an overall sensitivity of $99.3 \%$, a specificity of $94.6 \%$, and $91.5 \%(\kappa=0.91)$ agreement with MA [36].

An electrochemical immunosensor made of gold-based self-assembled monolayers of a carboxylic-groupterminated bipodal alkanethiol linked covalently to a $F$. tularensis LPS was developed to detect anti-F. tularensis antibodies [37]. This immunosensor could deliver a result after $30 \mathrm{~min}$ with a limit of detection of $15 \mathrm{ng} / \mathrm{mL}$ (RSD of $9 \%, \mathrm{n}=3$ ) when testing serum from tularemic animals.

A gold nanoparticle-based oligonucleotide-linked immunosorbent assay (GNP-OLISA) that utilized antibody-gold nanoparticles conjugated with DNA strands as a signal generator and RNA oligonucleotides appended with a fluorophore as a quencher for signal amplification was modified by using one antibody for both the capture of the target and for signal generation instead of using two different antibodies for the detection of F. tularensis. The modified GNPOLISA showed 37-fold higher sensitivity in sera samples than that of ELISA and the detection specificity was not affected by the presence of non-target bacteria, suggesting that GNP-OLISA could overcome the limit of the conventional assay system and be used as a sensitive detection platform for monitoring high-risk pathogens [38].

\subsection{Other Assays}

Surface enhanced laser desorption ionization time-of-flight mass spectrometry (SELDI-TOF/MS) was first utilized two decades ago to discriminate between the 4 subspecies of $F$. tularensis [39] and the method was based on the differential binding of protein subsets to chemically modified surfaces. Bacterial thermolysates were added to cationic, anionic, and copper ion-loaded immobilized metal affinity SELDI chip surfaces for binding. After washing, the spectra generated from the different surfaces were then obtained and the SELDI-TOF/MS profiles of different proteins were 
then used to characterize each $F$. tularensis strain.

MALDI-TOF/MS spectra acquired on a virulent $F$. tularensis strain and a $F$. philomiragia strain confirmed the intense peaks of the $10 \mathrm{kDa}$ chaperonin Cpn10, the 50S ribosomal protein L24, the histone-like protein HU form B, and their predicted molecular weights in terms of $\mathrm{m} / \mathrm{z}$, which made the mass spectrometry method possible to distinguish between virulent and nonvirulent Francisella strains in a quick and robust manner [40]. MALDI-TOF/MS was tested for its ability to identify and discriminate 50 different strains of the genus Francisella with already known species and subspecies and it could classify 2 isolates as Francisella species and 7 strains as F. tularensis on a microflex LT mass spectrometer using MALDI Biotyper version 3.0 software [41]. Spectra generated from a single analysis were queued with the Biotyper reference library with or without SR library supplementation and further analyzed with the help of both libraries.

Cy5-labeled, PCR-generated rrs gene amplicons of both target and non-target bacteria were hybridized in DNA microarrays and the mean fluorescence of a positive sample was at least $10 \%$ of that of a positive control. The $r r s$ gene of samples with values around the threshold were further analyzed by quantitative PCRs. The detection limit for Francisella spp. was only 1 genome copy with no unspecific cross-reactions and the general detection limit for other agents was about $10^{3}$ genome copies, corresponding to 1-2 pg of DNA [42].

The combination of the conventional sandwich-ELISA using streptavidin-poly-horseradish peroxidase as the signal amplifier with a microtube-integrated protein chip enabled simultaneous detection of a multitude of different biowarfare agents [43]. Specific immunoassays for F. tularensis and the rest of the listed agents were also developed and optimized and these assays could get results within $2 \mathrm{~h}$ with detection levels as low as those in well-established ELISAs. With careful antibody screening and testing, it had the potential to analyze at least 5 different agents in parallel on one single chip, which is most interesting.

Considering that pathogens are of different sizes, a bacterial detection system based on flow cytometry was designed to detect pathogens about the size of submicron by counting and interrogation of individual bacterium physically on a microfluidic chip through very narrow channels controlled by changing the respective flow rates of a sample solution and the liquid wall therein using a movable virtual wall (made of a non-conducting fluid). This bacterial sensor based on DC (direct current) impedance on chips was capable of discriminating different types of bacterial mixtures containing F. tularensis and E. coli BL21 of different size distributions due to its ability to monitor changes in DC impedance and fluorescence simultaneously [44].

\section{SIMULTANEOUS DETECTION OF FRANCISELLA AND OTHER SELECT AGENTS}

Three of the 6 Category A Select Agents (F.tularensis, B. anthracis, and Y. pestis) are the deadliest bacteria and their potential use in bioterrorism attacks is a concern as illustrated in the intentional release of $B$. anthracis in the United States in 2001. It also holds equal importance to be able to tell whether it is a true warning or a false alarm and whether it is the intentional use of biological warfare agents or natural outbreaks as discussed [45], and that relies on our capability to quickly and accurately differentiate the more virulent pathogens from the less virulent or environmental strains. To develop some procedure like "one (assay) for all (agents)" would be ideal. We have listed below the most recent reports of assays targeting multiple bioagents with various features like sensitivity (level of detection, LOD), specificity, and time of the procedure.

\subsection{PCR}

Several multiplex real-time PCRs have been designed for reliable and rapid detection of $F$. tularensis, B. anthracis, and $Y$. pestis and shown a high analytical specificity, sensitivity and coverage of the diverse pathogens [46].

Incorporating $10 \mathrm{PCR}$ assays together made possible to target 5 biological agents $(F$. tularensis, B. anthracis, B. mallei, B. pseudomallei, and Y. pestis) with a single TaqMan Array Card. When $100 \mathrm{fg}$ of the pathogen DNA extracted from pure bacterial cultures was added to the channels of Array Card, the detection level of the pathogen was $100 \%$, $93 \%, 71 \%$ and $43 \%$ for $Y$. pestis, B. mallei \& F. tularensis, B. anthracis, and B. pseudomallei respectively, which was further verified by singleplex format PCR [47].

The simplicity, specificity and sensitivity of 11 commercially available rapid test kits were compared in $\operatorname{detecting} F$. tularensis, Y. pestis, and B. anthracis [48]. Among the $11 \mathrm{kits}$, the immunofiltration assays were highly sensitive but with limited specificity and the procedure was far too complicated for non-laboratory workers. Although the lateral flow assays were easy to perform and rapid but its sensitivity was very limited. 
Contrary to the above example, here is a multiplexed PCR-based assay particularly suited for biothreat testing by operators with limited training. The FilmArray ${ }^{\circledR}$ platform was a sophisticated, almost complete sample-to-result system automated from sample preparation, PCR to data analysis for 17 pathogens and toxins. It was sensitive, selective and identification of $F$. tularensis was made in 63 of 72 samples at 25 genome equivalents (GEs) or less with no crossreactivity with near-neighbor DNAs. The limit of detection for B. anthracis and Y. pestis was 250 GEs per sample or lower [49].

A biological agent identification system based on the biobarcode assay and on-chip capillary electrophoresis (CE) analysis was developed and used to detect F. tularensis, B. anthracis, Y. pestis, Vaccinia virus with a detection limit of $50 \mathrm{CFU} / \mathrm{mL}$, and at a concentration of $12.5 \mathrm{ag} / \mathrm{mL}$ for Botulinum toxin A [50]. The working mechanism for the DNA barcode assay is that a specific pathogen can form complexes with the polystyrene microbead and the magnetic microparticle, and upon denaturation the single stranded barcode DNA labeled with FAM could be released from the complexes. The specific peak elution time in the CE on a chip representing the specific barcode DNA length of a certain pathogen allows to distinguish the target microbe within $3 \mathrm{~min}$ in a multiplex, accurate, and sensitive manner.

Luminex $^{\circledR} 100^{\mathrm{TM}}$ is a bead-based liquid hybridization assay and has been used to identify pathogens (F. tularensis, B. anthracis, C. botulinum, and $Y$. pestis, and several close relatives). Depending on the varying sensitivity ranged from 0.1 to $10 \mathrm{ng}$ of the probes for different microbes, signals could be detected in single-probe or multiple-probe assays after hybridization of PCR-amplified target sequences with probe sequences (located within the 23S ribosomal RNA gene $r r l$ and the virulence genes of a certain pathogen). Sensitivity could be improved by digesting the noncomplementary target strand with lambda exonuclease before the hybridization reaction. All contributors were identified with an $80 \%$ success rate in all the 33 binary, ternary, and quaternary mixture present in a 1:1 ratio. The assay could detect all the mixed 28 binary target sequences in different ratios, even when the minor component was 10 times less than the major component [51].

Two sensitive, flexible arrays were developed in one work to detect several biothreat pathogens simultaneously $(F$. tularensis, B. anthracis, Brucella spp., B. pseudomallei, and Y. pestis). One has utilized universal primers to amplify the highly conserved region located within the $16 \mathrm{~S}$ rRNA amplicon, and hybridized with probes specific for identification of these 5 microbes, which could detect as low as $0.2 \mathrm{pg} F$. tularensis or varying amount genomic DNA template for the rest agents in the PCR amplification reactions. Another assay based on multiplex PCR could simultaneously detect pathogens by amplifying 5 species-specific target unique identifier regions (fopA for F. tularensis), and significantly increase the discriminatory power of detection to the species level which was not seen from using the universal primers in the $1^{\text {st }}$ assay [52].

As the non-spore-forming and most stable organism in water, $F$. tularensis has a potential to survive and grow in this environment as summarized [53]. A useful technique that could specifically and simultaneously detect in tap water the faecal indicator bacteria and human pathogens (F. tularensis, C. parvum, C. hominis, E. faecium, and B. anthracis) was developed with a DNA microarray containing probes for these microbes [54].

Francisella is closely related to the environment and a lot of effort has already been made on differentiating the highly infectious $F$. tularensis strains from other less virulent Francisella isolates from water and soil, such as $F$. noatunensis, $F$. philomiragia and $F$. novicida. Two real-time quantitative PCR assays (monoplex or multiplex) were developed that could specifically differentiate $F$. philomiragia from $F$. noatunensis with a LOD of 10 genome equivalents [55]. Interestingly, a pair of eubacterial 16S rRNA primers amplified a product of 550 bp (part of the 16S rRNA of Francisella) from bass kidney, which led to the finding of F. noatunensis, a novel species of Francisella [56]. More than a decade ago, a TaqMan PCR was elegantly designed to target 3 genes (ISFtu2, iglC, and tul4) so that the difference of $\mathrm{Ct}$ values in ISFtu2 PCR could tell F. philomiragia (average Ct, 33) from F. tularensis (average Ct, 14) with a sensitivity of about $1 \mathrm{CFU}$ or GE [57].

\subsection{Surveillance of Antibiotic Resistance}

Antibiotic treatment is a therapeutic strategy for tularemia and its resistance, whether spontaneous or intentionally engineered, remains a national security and public health concern. Besides the disc method for assaying antibiotic resistance, there are molecular techniques available to determine the resistance mechanism. For example, several assays were compared for their ability rapidly detecting one or more known mutations within the $\operatorname{gyr} \mathrm{A}, \operatorname{gyr} \mathrm{B}, \operatorname{par} \mathrm{C}$, and $\operatorname{par} \mathrm{E}$ genes of the quinolone resistance-determining region (QRDR) in ciprofloxacin-resistant $F$. tularensis, B. anthracis, and $Y$. pestis. Among them, Pyrosequencing and SimpleProbe successfully found all the known mutations whereas the 
HRM assay could identify all but those generated from G-C or A-T substitutions [58].

An SNP-based Multiplexed Oligonucleotide Ligation-PCR (MOL-PCR) was developed and used for rapid characterization of ciprofloxacin and doxycycline resistance in and simultaneous detection of $F$. tularensis, B. anthracis, and $Y$. pestis [59]. A similar approach utilizing qPCR was able to detect acquired resistance of $F$. tularensis by measuring the minimal inhibitory extracellular concentration of antibiotics indicative of its intracellular activity [60]. A web-based tool called MOLigoDesigner (http://MOLigoDesigner.lanl.gov) was provided to keep the making of all probes minimal, and all the multiplex assays were validated individually. A genotyping pipeline, CanSNPer, was developed with the Python language where preconstructed typing schemes for F. tularensis, B. anthracis, Y. pestis, and C. burnetii were available for analysis of canonical SNPs [61]. The obvious advantage of this pipeline is that one can modify and improve it by adding additional pathogens and optimizing the classification algorithm.

\subsection{Other Assays}

Laser-induced breakdown spectroscopy (LIBS) was used to differentiate among all dead and live bacteria on agar or glass slides as substrates with either $F$. tularensis live vaccine strain or B. anthracis Sterne strain grown as lawn, single colony or even in solution [62]. Francisella specific monoclonal antibodies could be covalently coated onto the upconverting phosphor particles to make the lateral flow assay to detect $F$. tularensis in a fast (15 min), sensitive (100 CFU/test), and low error fashion [63]. A nanoprobe that was made by apoferritin nanoparticles genetically engineered and conjugated with antibodies with different fluorescent dyes could detect F. tularensis, B. anthracis, Y. pestis and Vaccinia virus, 10 times more sensitive than regular lateral flow devices [64].

\section{FUTURE PERSPECTIVES}

Although $F$. tularensis has been identified in more than 300 species of invertebrates, amphibians, birds, and mammals, still its overall ecology is poorly understood. The type A F. tularensis infections in humans are most often associated with exposure to blood-feeding arthropods, lagomorphs, rodents, and the type B F. holarctica infections are also associated with rivers, streams, and flooded landscapes. Table 1 summarized in an oversimplified manner the features of some assays as reported [65 - 76] and reviewed [53, 77 - 79] for Francisella detection from case (animal, human) samples or the environment (air, water, plants). It is true that molecular genetic analysis of F. tularensis has been greatly helped by the availability of the many complete and published genome sequences. Better understanding of $F$. tularensis, more whole $F$. tularensis genome sequences [25 - 28, 80 - 88], and advanced technology in general will be needed and definitely help develop more rapid, accurate and automated assays, making the identification and characterization of $F$. tularensis easier and hopefully keeping its threat under bay.

\section{CONCLUSION}

Molecular techniques should be the $1^{\text {st }}$ option of choice when it comes to answer the questions whether it is a Francisella infection and what kind of Francisella is it? When feasible, complementing these molecular techniques with other assays like whole genome sequencing and physiochemical instruments makes the answer come out faster, more convincing and reliable.

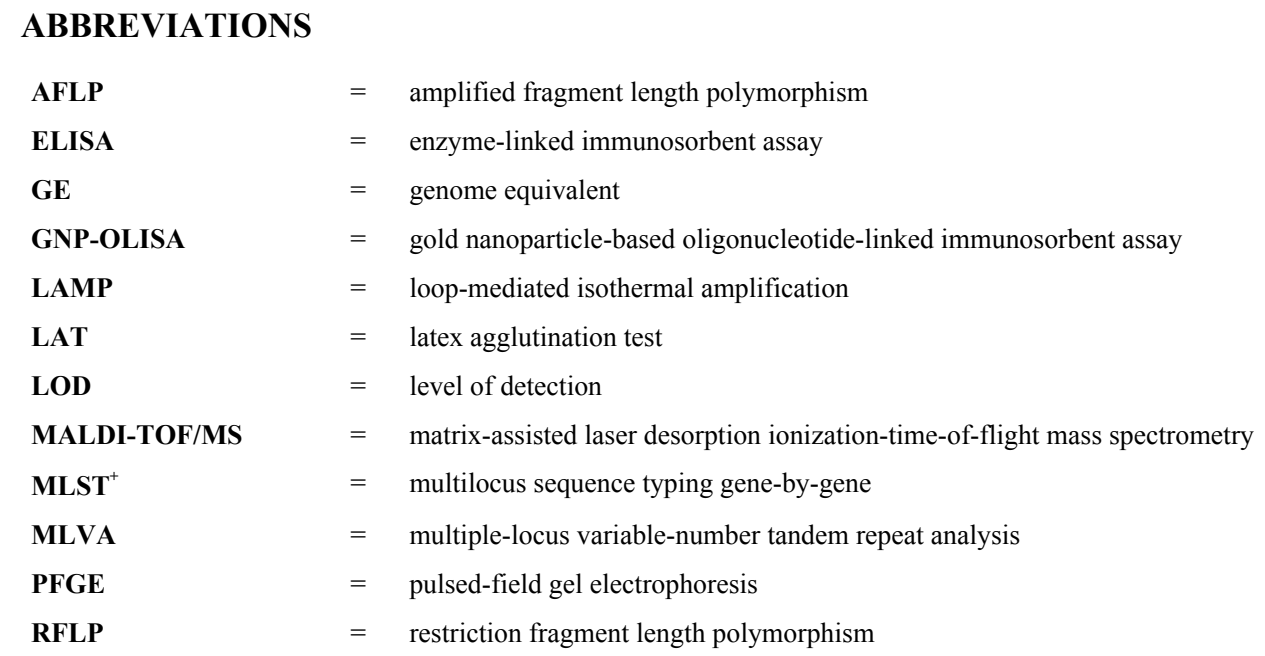




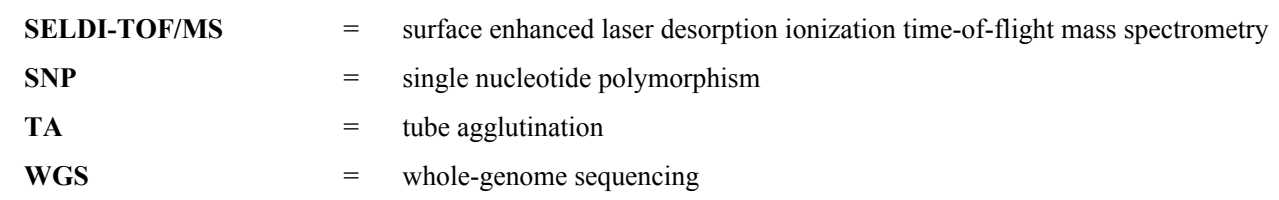

\section{CONFLICT OF INTEREST}

The authors confirm that this article content has no conflict of interest. The authors also have no relevant affiliations or financial involvement with any organization or entity with a financial interest in or financial conflict with the subject matter or materials discussed in the manuscript, including employment, consultancies, honoraria, stock ownership or options, expert testimony, grants or patents received or pending, or royalties.

\section{ACKNOWLEDGEMENTS}

We appreciate the comments from the anonymous reviewers on revising our manuscript.

\section{REFERENCES}

[1] Dennis DT, Inglesby TV, Henderson DA, et al. Tularemia as a biological weapon: medical and public health management. JAMA 2001; 285(21): 2763-73. [http://dx.doi.org/10.1001/jama.285.21.2763] [PMID: 11386933]

[2] Keim PS, Wagner DM. Humans and evolutionary and ecological forces shaped the phylogeography of recently emerged diseases. Nat Rev Microbiol 2009; 7(11): 813-21.

[http://dx.doi.org/10.1038/nrmicro2219] [PMID: 19820723]

[3] Anonymous . Anonymous, Tularemia surveillance case definition. US Department of Health and Human Services, CDC, Atlanta, GA. Available online at http://wwwn.cdc.gov/nndss/script/casedef.aspx?condyrid=880\&datepub=1/1/1999\%2012:00:00\%20am. Accessed on 2015 December 31 .

[4] Anonymous. US Department of Health and Human Services, CDC, Atlanta, GA. Available online at http://www.bt.cdc.gov/ 1rn/biological.asp. [Accessed on 2015 December 31]

[5] Nirkhiwale SD, Gehlot GS, Bandi AK, Jasani AN. Isolation of Francisella tularensis from blood culture. Indian J Med Microbiol 2015; 33(2): 329-31. [http://dx.doi.org/10.4103/0255-0857.154901] [PMID: 25866005]

[6] Becker S, Lochau P, Jacob D, Heuner K, Grunow R. Successful re-evaluation of broth medium T for growth of Francisella tularensis ssp. and other highly pathogenic bacteria J Microbiol Methods 2016; 121: 5-7. [http://dx.doi.org/10.1016/j.mimet.2015.11.018] [PMID: 26658853]

[7] Lamont EA, Wang P, Enomoto S, et al. A combined enrichment and aptamer pulldown assay for Francisella tularensis detection in food and environmental matrices. PLoS One 2014; 9(12): e114622. [http://dx.doi.org/10.1371/journal.pone.0114622] [PMID: 25536105]

[8] Sissonen S, Rossow H, Karlsson E, et al. Phylogeography of Francisella tularensis subspecies holarctica in Finland, 1993-2011. Infect Dis (Lond) 2015; 47(10): 701-6. [http://dx.doi.org/10.3109/23744235.2015.1049657] [PMID: 26004621]

[9] Kugeler KJ, Mead PS, Janusz AM, et al. Molecular Epidemiology of Francisella tularensis in the United States. Clin Infect Dis 2009; 48(7): 863-70. [http://dx.doi.org/10.1086/597261] [PMID: 19245342]

[10] Vogler AJ, Birdsell D, Price LB, et al. Phylogeography of Francisella tularensis: global expansion of a highly fit clone J Bacteriol 2009; 191(8): 2474-84. [http://dx.doi.org/10.1128/JB.01786-08] [PMID: 19251856]

[11] Birdsell DN, Johansson A, Öhrman C, et al. Francisella tularensis subsp. tularensis group A.I, United States Emerg Infect Dis 2014; 20(5): $861-5$.

[http://dx.doi.org/10.3201/eid2005.131559] [PMID: 24755401]

[12] Farlow J, Smith KL, Wong J, Abrams M, Lytle M, Keim P. Francisella tularensis strain typing using multiple-locus, variable-number tandem repeat analysis. J Clin Microbiol 2001; 39(9): 3186-92. [http://dx.doi.org/10.1128/JCM.39.9.3186-3192.2001] [PMID: 11526148]

[13] Wang YH, Qiao FY, Cao J, et al. A case of Francisella tularensis subspecies holarctica in China. Ticks Tick Borne Dis 2015; 6(6): 802-4. [http://dx.doi.org/10.1016/j.ttbdis.2015.07.007] [PMID: 26210091]

[14] Forsman M, Sandström G, Sjöstedt A. Analysis of 16S ribosomal DNA sequences of Francisella strains and utilization for determination of the phylogeny of the genus and for identification of strains by PCR. Int J Syst Bacteriol 1994; 44(1): 38-46. [http://dx.doi.org/10.1099/00207713-44-1-38] [PMID: 8123561] 
[15] Gunnell MK, Adams BJ, Robison RA. The genetic diversity and evolution of francisella tularensis with comments on detection by PCR. Curr Issues Mol Biol 2015; 18: 79-92. [PMID: 26336102]

[16] Bushon RN, Kephart CM, Koltun GF, Francy DS, Schaefer FW III, Alan Lindquist HD. Statistical assessment of DNA extraction reagent lot variability in real-time quantitative PCR. Lett Appl Microbiol 2010; 50(3): 276-82. [http://dx.doi.org/10.1111/j.1472-765X.2009.02788.x] [PMID: 20070509]

[17] Buzard GS, Baker D, Wolcott MJ, Norwood DA, Dauphin LA. Multi-platform comparison of ten commercial master mixes for probe-based real-time polymerase chain reaction detection of bioterrorism threat agents for surge preparedness. Forensic Sci Int 2012; $223(1-3)$ : 292-7. [http://dx.doi.org/10.1016/j.forsciint.2012.10.003] [PMID: 23107058]

[18] Dauphin LA, Walker RE, Petersen JM, Bowen MD. Comparative evaluation of automated and manual commercial DNA extraction methods for detection of Francisella tularensis DNA from suspensions and spiked swabs by real-time polymerase chain reaction. Diagn Microbiol Infect Dis 2011; 70(3): 299-306.

[http://dx.doi.org/10.1016/j.diagmicrobio.2011.02.010] [PMID: 21546201]

[19] Trombley Hall A, McKay Zovanyi A, Christensen DR, Koehler JW, Devins Minogue T. Evaluation of inhibitor-resistant real-time PCR methods for diagnostics in clinical and environmental samples. PLoS One 2013; 8(9): e73845. [http://dx.doi.org/10.1371/journal.pone.0073845] [PMID: 24040090]

[20] Whitehouse CA, Hottel HE. Comparison of five commercial DNA extraction kits for the recovery of Francisella tularensis DNA from spiked soil samples. Mol Cell Probes 2007; 21(2): 92-6. [http://dx.doi.org/10.1016/j.mcp.2006.08.003] [PMID: 17011748]

[21] Matero P, Hemmilä H, Tomaso H, et al. Rapid field detection assays for Bacillus anthracis, Brucella spp., Francisella tularensis and Yersinia pestis. Clin Microbiol Infect 2011; 17(1): 34-43. [http://dx.doi.org/10.1111/j.1469-0691.2010.03178.x] [PMID: 20132255]

[22] Mölsä M, Hemmilä H, Katz A, et al. Monitoring biothreat agents (Francisella tularensis, Bacillus anthracis and Yersinia pestis) with a portable real-time PCR instrument. J Microbiol Methods 2015; 115: 89-93. [http://dx.doi.org/10.1016/j.mimet.2015.05.026] [PMID: 26043838]

[23] Turingan RS, Thomann HU, Zolotova A, Tan E, Selden RF. Rapid focused sequencing: a multiplexed assay for simultaneous detection and strain typing of Bacillus anthracis, Francisella tularensis, and Yersinia pestis. PLoS One 2013; 8(2): e56093. [http://dx.doi.org/10.1371/journal.pone.0056093] [PMID: 23418519]

[24] Rydzewski K, Schulz T, Brzuszkiewicz E, et al. Genome sequence and phenotypic analysis of a first German Francisella sp. isolate (W12-1067) not belonging to the species Francisella tularensis. BMC Microbiol 2014; 14: 169. [http://dx.doi.org/10.1186/1471-2180-14-169] [PMID: 24961323]

[25] Johansson A, Lärkeryd A, Widerström M, et al. An outbreak of respiratory tularemia caused by diverse clones of Francisella tularensis. Clin Infect Dis 2014; 59(11): 1546-53. [http://dx.doi.org/10.1093/cid/ciu621] [PMID: 25097081]

[26] Afset JE, Larssen KW, Bergh K, et al. Phylogeographical pattern of Francisella tularensis in a nationwide outbreak of tularaemia in Norway, 2011. Euro Surveill 2015; 20(19): 9-14. [http://dx.doi.org/10.2807/1560-7917.ES2015.20.19.21125] [PMID: 25990357]

[27] Larson MA, Nalbantoglu U, Sayood K, et al. Francisella tularensis Subtype A.II Genomic Plasticity in Comparison with Subtype A.I. PLoS One 2014; 10(4): e0124906.

[http://dx.doi.org/10.1371/journal.pone.0124906] [PMID: 25918839]

[28] Antwerpen MH, Prior K, Mellmann A, Höppner S, Splettstoesser WD, Harmsen D. Rapid high resolution genotyping of Francisella tularensis by whole genome sequence comparison of annotated genes ("MLST"). PLoS One 2015; 10(4): e0123298. [http://dx.doi.org/10.1371/journal.pone.0123298] [PMID: 25856198]

[29] http://www.globalmicrobialidentifier.org Accessed on 2015 December 31.

[30] Cooper KL, Bandara AB, Wang Y, Wang A, Inzana TJ. Photonic biosensor assays to detect and distinguish subspecies of Francisella tularensis. Sensors (Basel) 2011; 11(3): 3004-19. [http://dx.doi.org/10.3390/s110303004] [PMID: 22163782]

[31] Rastawicki W, Rokosz-Chudziak N, Chróst A, Gierczyński R. Development and evaluation of a latex agglutination test for the rapid serodiagnosis of tularemia. J Microbiol Methods 2015; 112: 1-2. [http://dx.doi.org/10.1016/j.mimet.2015.02.012] [PMID: 25727796]

[32] Sharma N, Hotta A, Yamamoto Y, et al. Detection of Francisella tularensis-specific antibodies in patients with tularemia by a novel competitive enzyme-linked immunosorbent assay. Clin Vaccine Immunol 2013; 20(1): 9-16. [http://dx.doi.org/10.1128/CVI.00516-12] [PMID: 23114700]

[33] Sharma N, Hotta A, Yamamoto Y, et al. Serosurveillance for Francisella tularensis among wild animals in Japan using a newly developed competitive enzyme-linked immunosorbent assay. Vector Borne Zoonotic Dis 2014; 14(4): 234-9. [http://dx.doi.org/10.1089/vbz.2013.1349] [PMID: 24689989]

[34] Chaignat V, Djordjevic-Spasic M, Ruettger A, et al. Performance of seven serological assays for diagnosing tularemia. BMC Infect Dis 2014; 
14: 234 .

[http://dx.doi.org/10.1186/1471-2334-14-234] [PMID: 24885274]

[35] Rastawicki W, Wolaniuk N. [Comparison of usefulness of commercial ELISA Virion/Serion, homemade ELISA and tube agglutination test in serodiagnosis of tularemia]. Med Dosw Mikrobiol 2013; 65(4): 255-61. [PMID: 24730213]

[36] Kiliç S, Celebi B, Yeşilyurt M. Evaluation of a commercial immunochromatographic assay for the serologic diagnosis of tularemia. Diagn Microbiol Infect Dis 2012; 74(1): 1-5. [http://dx.doi.org/10.1016/j.diagmicrobio.2012.05.030] [PMID: 22770772]

[37] Dulay SB, Julich S, Tomaso H, O’Sullivan CK. Development of an immunosensor for the detection of Francisella tularensis antibodies. Anal Bioanal Chem 2014; 406(19): 4685-90.

[http://dx.doi.org/10.1007/s00216-014-7860-2] [PMID: 24817365]

[38] Seo SH, Lee YR, Ho Jeon J, et al. Highly sensitive detection of a bio-threat pathogen by gold nanoparticle-based oligonucleotide-linked immunosorbent assay. Biosens Bioelectron 2015; 64: 69-73. [http://dx.doi.org/10.1016/j.bios.2014.08.038] [PMID: 25194798]

[39] Lundquist M, Caspersen MB, Wikström P, Forsman M. Discrimination of Francisella tularensis subspecies using surface enhanced laser desorption ionization mass spectrometry and multivariate data analysis. FEMS Microbiol Lett 2005; 243(1): 303-10. [http://dx.doi.org/10.1016/j.femsle.2004.12.020] [PMID: 15668033]

[40] Durighello E, Bellanger L, Ezan E, Armengaud J. Proteogenomic biomarkers for identification of Francisella species and subspecies by matrix-assisted laser desorption ionization-time-of-flight mass spectrometry. Anal Chem 2014; 86(19): 9394-8. [http://dx.doi.org/10.1021/ac501840g] [PMID: 25215633]

[41] Seibold E, Maier T, Kostrzewa M, Zeman E, Splettstoesser W. Identification of Francisella tularensis by whole-cell matrix-assisted laser desorption ionization-time of flight mass spectrometry: fast, reliable, robust, and cost-effective differentiation on species and subspecies levels. J Clin Microbiol 2010; 48(4): 1061-9.

[http://dx.doi.org/10.1128/JCM.01953-09] [PMID: 20181907]

[42] Melničáková J, Derdáková M, Barák I. A system to simultaneously detect tick-borne pathogens based on the variability of the 16S ribosomal genes. Parasit Vectors 2013; 6: 269. [http://dx.doi.org/10.1186/1756-3305-6-269] [PMID: 24330462]

[43] Huelseweh B, Ehricht R, Marschall HJ. A simple and rapid protein array based method for the simultaneous detection of biowarfare agents. Proteomics 2006; 6(10): 2972-81.

[http://dx.doi.org/10.1002/pmic.200500721] [PMID: 16622830]

[44] Choi H, Jeon CS, Hwang I, et al. A flow cytometry-based submicron-sized bacterial detection system using a movable virtual wall. Lab Chip 2014; 14(13): 2327-33. [http://dx.doi.org/10.1039/c4lc00238e] [PMID: 24828279]

[45] Grunow R, Finke EJ. A procedure for differentiating between the intentional release of biological warfare agents and natural outbreaks of disease: its use in analyzing the tularemia outbreak in Kosovo in 1999 and 2000. Clin Microbiol Infect 2002; 8(8): 510-21. [http://dx.doi.org/10.1046/j.1469-0691.2002.00524.x] [PMID: 12197873]

[46] Janse I, Hamidjaja RA, Bok JM, van Rotterdam BJ. Reliable detection of Bacillus anthracis, Francisella tularensis and Yersinia pestis by using multiplex qPCR including internal controls for nucleic acid extraction and amplification. BMC Microbiol 2010; 10 : 314. [PMID: 21143837]

[47] Rachwal PA, Rose HL, Cox V, Lukaszewski RA, Murch AL, Weller SA. The potential of TaqMan Array Cards for detection of multiple biological agents by real-time PCR. PLoS One 2012; 7(4): e35971. [http://dx.doi.org/10.1371/journal.pone.0035971] [PMID: 22540014]

[48] Zasada AA, Formińska K, Zacharczuk K, Jacob D, Grunow R. Comparison of eleven commercially available rapid tests for detection of Bacillus anthracis, Francisella tularensis and Yersinia pestis. Lett Appl Microbiol 2015; 60(5): 409-13. [http://dx.doi.org/10.1111/lam.12392] [PMID: 25598285]

[49] Seiner DR, Colburn HA, Baird C, et al. Evaluation of the FilmArray ${ }^{\circledR}$ system for detection of Bacillus anthracis, Francisella tularensis and Yersinia pestis. J Appl Microbiol 2013; 114(4): 992-1000. [http://dx.doi.org/10.1111/jam.12107] [PMID: 23279070]

[50] Cho M, Chung S, Jung JH, Rhie GE, Jeon JH, Seo TS. Combination of biobarcode assay with on-chip capillary electrophoresis for ultrasensitive and multiplex biological agent detection. Biosens Bioelectron 2014; 61: 172-6. [http://dx.doi.org/10.1016/j.bios.2014.05.018] [PMID: 24878840]

[51] Schweighardt AJ, Battaglia A, Wallace MM. Detection of anthrax and other pathogens using a unique liquid array technology. J Forensic Sci 2014; 59(1): 15-33. [http://dx.doi.org/10.1111/1556-4029.12283] [PMID: 24147813]

[52] Yang Y, Wang J, Wen H, Liu H. Comparison of two suspension arrays for simultaneous detection of five biothreat bacterial in powder samples. J Biomed Biotech 2012; 2012: 831052.

[http://dx.doi.org/10.1155/2012/831052] 
[53] Colquhoun DJ, Duodu S. Francisella infections in farmed and wild aquatic organisms. Vet Res 2011; $42: 47$. [http://dx.doi.org/10.1186/1297-9716-42-47] [PMID: 21385413]

[54] Brinkman NE, Francisco R, Nichols TL, et al. Detection of multiple waterborne pathogens using microsequencing arrays. J Appl Microbiol 2013; 114(2): 564-73.

[http://dx.doi.org/10.1111/jam.12073] [PMID: 23167710]

[55] Duodu S, Larsson P, Sjödin A, Soto E, Forsman M, Colquhoun DJ. Real-time PCR assays targeting unique DNA sequences of fishpathogenic Francisella noatunensis subspecies noatunensis and orientalis. Dis Aquat Organ 2012; 101(3): 225-34. [http://dx.doi.org/10.3354/dao02514] [PMID: 23324419]

[56] Ostland VE, Stannard JA, Creek JJ, et al. Aquatic Francisella-like bacterium associated with mortality of intensively cultured hybrid striped bass Morone chrysops x M. saxatilis. Dis Aquat Organ 2006; 72(2): 135-45. [http://dx.doi.org/10.3354/dao072135] [PMID: 17140136]

[57] Versage JL, Severin DD, Chu MC, Petersen JM. Development of a multitarget real-time TaqMan PCR assay for enhanced detection of Francisella tularensis in complex specimens. J Clin Microbiol 2003; 41(12): 5492-9. [http://dx.doi.org/10.1128/JCM.41.12.5492-5499.2003] [PMID: 14662930]

[58] Loveless BM, Yermakova A, Christensen DR, et al. Identification of ciprofloxacin resistance by simpleProbe, high resolution melt and pyrosequencing nucleic acid analysis in biothreat agents: bacillus anthracis, yersinia pestis and francisella tularensis. Mol Cell Probes 2010; 24(3): 154-60.

[http://dx.doi.org/10.1016/j.mcp.2010.01.003] [PMID: 20100564]

[59] Song J, Li PE, Gans J, et al. Simultaneous pathogen detection and antibiotic resistance characterization using SNP-based multiplexed oligonucleotide ligation-PCR (MOL-PCR). Adv Exp Med Biol 2010; 680: 455-64. [http://dx.doi.org/10.1007/978-1-4419-5913-3_51] [PMID: 20865530]

[60] Aloni-Grinstein R, Shifman O, Lazar S, Steinberger-Levy I, Maoz S, Ber R. A rapid real-time quantitative PCR assay to determine the minimal inhibitory extracellular concentration of antibiotics against an intracellular Francisella tularensis Live Vaccine Strain. Front Microbiol 2015; 6: 1213. [http://dx.doi.org/10.3389/fmicb.2015.01213] [PMID: 26579112]

[61] Lärkeryd A, Myrtennäs K, Karlsson E, et al. CanSNPer: a hierarchical genotype classifier of clonal pathogens. Bioinformatics 2014; 30(12): 1762-4. [http://dx.doi.org/10.1093/bioinformatics/btu113] [PMID: 24574113]

[62] Multari RA, Cremers DA, Bostian ML. Use of laser-induced breakdown spectroscopy for the differentiation of pathogens and viruses on substrates. Appl Opt 2012; 51(7): B57-64. [http://dx.doi.org/10.1364/AO.51.000B57] [PMID: 22410926]

[63] Hua F, Zhang P, Zhang F, et al. Development and evaluation of an up-converting phosphor technology-based lateral flow assay for rapid detection of Francisella tularensis. Sci Rep 2015; 5: 17178. [http://dx.doi.org/10.1038/srep17178] [PMID: 26608358]

[64] Seo Y, Kim JE, Jeong Y, et al. Engineered nanoconstructs for the multiplexed and sensitive detection of high-risk pathogens. Nanoscale 2015. [Epub ahead of print] [PMID: 26462853]

[65] Koskela P, Salminen A. Humoral immunity against Francisella tularensis after natural infection. J Clin Microbiol 1985; $22(6)$ : 973-9. [PMID: 4066925]

[66] Fey PD, Dempsey MM, Olson ME, et al. Molecular analysis of Francisella tularensis subspecies tularensis and holarctica. Am J Clin Pathol 2007; 128(6): 926-35

[http://dx.doi.org/10.1309/JN3NTHK4VVWKJT4A] [PMID: 18024317]

[67] Kalasinsky KS, Hadfield T, Shea AA, et al. Raman chemical imaging spectroscopy reagentless detection and identification of pathogens: signature development and evaluation. Anal Chem 2007; 79(7): 2658-73. [http://dx.doi.org/10.1021/ac0700575] [PMID: 17338507]

[68] Grif K, Dierich MP, Much P, Hofer E, Allerberger F. Identifying and subtyping species of dangerous pathogens by automated ribotyping. Diagn Microbiol Infect Dis 2003; 47(1): 313-20. [http://dx.doi.org/10.1016/S0732-8893(03)00095-6] [PMID: 12967744]

[69] Forsman M, Sandström G, Jaurin B. Identification of Francisella species and discrimination of type A and type B strains of F. tularensis by 16S rRNA analysis. Appl Environ Microbiol 1990; 56(4): 949-55. [PMID: 1692676]

[70] García Del Blanco N, Dobson ME, Vela AI, et al. Genotyping of Francisella tularensis strains by pulsed-field gel electrophoresis, amplified fragment length polymorphism fingerprinting, and 16S rRNA gene sequencing. J Clin Microbiol 2002; 40(8): $2964-72$. [http://dx.doi.org/10.1128/JCM.40.8.2964-2972.2002] [PMID: 12149360]

[71] Ibrahim A, Gerner-Smidt P, Sjöstedt A. Amplification and restriction endonuclease digestion of a large fragment of genes coding for rRNA as a rapid method for discrimination of closely related pathogenic bacteria. J Clin Microbiol 1996; 34(12): $2894-6$. [PMID: 8940418] 
[72] Johansson A, Farlow J, Larsson P, et al. Worldwide genetic relationships among Francisella tularensis isolates determined by multiple-locus variable-number tandem repeat analysis. J Bacteriol 2004; 186(17): 5808-18. [http://dx.doi.org/10.1128/JB.186.17.5808-5818.2004] [PMID: 15317786]

[73] Pandya GA, Holmes MH, Petersen JM, et al. Whole genome single nucleotide polymorphism based phylogeny of Francisella tularensis and its application to the development of a strain typing assay. BMC Microbiol 2009; 9: 213. [http://dx.doi.org/10.1186/1471-2180-9-213] [PMID: 19811647]

[74] Higgins JA, Hubalek Z, Halouzka J, et al. Detection of Francisella tularensis in infected mammals and vectors using a probe-based polymerase chain reaction. Am J Trop Med Hyg 2000; 62(2): 310-8.

[PMID: 10813490]

[75] Broekhuijsen M, Larsson P, Johansson A, et al. Genome-wide DNA microarray analysis of Francisella tularensis strains demonstrates extensive genetic conservation within the species but identifies regions that are unique to the highly virulent $\mathrm{F}$. tularensis subsp. tularensis. $\mathrm{J}$ Clin Microbiol 2003; 41(7): 2924-31.

[http://dx.doi.org/10.1128/JCM.41.7.2924-2931.2003] [PMID: 12843022]

[76] Caipang CM, Kulkarni A, Brinchmann MF, Korsnes K, Kiron V. Detection of Francisella piscicida in Atlantic cod (Gadus morhua L) by the loop-mediated isothermal amplification (LAMP) reaction. Vet J 2010; 184(3): 357-61. [http://dx.doi.org/10.1016/j.tvj1.2009.03.027] [PMID: 19398357]

[77] Johansson A, Forsman M, Sjöstedt A. The development of tools for diagnosis of tularemia and typing of Francisella tularensis. APMIS 2004; 112(11-12): 898-907. [http://dx.doi.org/10.1111/j.1600-0463.2004.apm11211-1212.x] [PMID: 15638842]

[78] Splettstoesser WD, Tomaso H, Al Dahouk S, Neubauer H, Schuff-Werner P. Diagnostic procedures in tularaemia with special focus on molecular and immunological techniques. J Vet Med B Infect Dis Vet Public Health 2005; 52(6): 249-61. [http://dx.doi.org/10.1111/j.1439-0450.2005.00863.x] [PMID: 16219088]

[79] Wagar E. Bioterrorism and the role of the clinical microbiology laboratory. Clin Microbiol Rev 2016; 29(1): 175-89. [Review]. [http://dx.doi.org/10.1128/CMR.00033-15] [PMID: 26656673]

[80] Sjödin A, Svensson K, Ohrman C, et al. Genome characterisation of the genus Francisella reveals insight into similar evolutionary paths in pathogens of mammals and fish. BMC Genomics 2012; 13: 268. [http://dx.doi.org/10.1186/1471-2164-13-268] [PMID: 22727144]

[81] Zeytun A, Malfatti SA, Vergez LM, Shin M, Garcia E, Chain PS. Complete genome sequence of Francisella philomiragia ATCC 25017. J Bacteriol 2012; 194(12): 3266. [http://dx.doi.org/10.1128/JB.00413-12] [PMID: 22628499]

[82] Siddaramappa S, Challacombe JF, Petersen JM, Pillai S, Kuske CR. Genetic diversity within the genus Francisella as revealed by comparative analyses of the genomes of two North American isolates from environmental sources. BMC Genomics 2012; 13 : 422. [http://dx.doi.org/10.1186/1471-2164-13-422] [PMID: 22920915]

[83] Sridhar S, Sharma A, Kongshaug H, Nilsen F, Jonassen I. Whole genome sequencing of the fish pathogen Francisella noatunensis subsp. orientalis Toba04 gives novel insights into Francisella evolution and pathogenecity. BMC Genomics 2012; 13 : 598. [http://dx.doi.org/10.1186/1471-2164-13-598] [PMID: 23131096]

[84] Davenport KW, Daligault HE, Minogue TD, et al. Whole-genome sequences of nine francisella isolates. Genome Announc 2014; 2(5): e00941-14. [http://dx.doi.org/10.1128/genomeA.00941-14] [PMID: 25291764]

[85] Johnson SL, Daligault HE, Davenport KW, et al. Genome sequencing of 18 francisella strains to aid in assay development and testing. Genome Announc 2015; 3(2): e00147-15.

[http://dx.doi.org/10.1128/genomeA.00147-15] [PMID: 25931589]

[86] Atkins LM, Holder ME, Ajami NJ, et al. High-quality draft genome sequence of francisella tularensis subsp. holarctica strain OR96-0246. Genome Announc 2015; 3(4): e00898-15. [http://dx.doi.org/10.1128/genomeA.00898-15] [PMID: 26272574]

[87] Johnson SL, Minogue TD, Daligault HE, et al. Finished genome assembly of warm spring isolate francisella novicida DPG 3A-IS. Genome Announc 2015; 3(5): e01046-15.

[http://dx.doi.org/10.1128/genomeA.01046-15] [PMID: 26383665]

[88] Song L, Yu Y, Feng L, et al. Draft genome sequence of francisella tularensis strain 410108 from Tibet, China. Genome Announc 2015; 3(6): e01489-15.

[http://dx.doi.org/10.1128/genomeA.01489-15] [PMID: 26679594]

Received: July 13, $2015 \quad$ Revised: October 20, $2015 \quad$ Accepted: October 22, 2015

(C) Lai et al. ; Licensee Bentham Open.

This is an open access article licensed under the terms of the Creative Commons Attribution-Non-Commercial 4.0 International Public License (CC BY-NC 4.0) (https://creativecommons.org/licenses/by-nc/4.0/legalcode), which permits unrestricted, non-commercial use, distribution and reproduction in any medium, provided the work is properly cited. 